\title{
Cytotoxicity evaluation of luting resin cements on bovine dental pulp-derived cells (bDPCs) by real-time cell analysis
}

\author{
Meral ARSLAN MALKOÇ ${ }^{1}$, Necla DEMIR ${ }^{2}$, Abdulkadir ŞENGÜN³ , Şerife Buket BOZKURT ${ }^{4}$ and Sema Sezen HAKKI ${ }^{5}$ \\ ${ }^{1}$ Department of Prosthodontics, Faculty of Dentistry, Inönü University, Malatya, Turkey \\ ${ }^{2}$ Department of Prosthodontics, Faculty of Dentistry, Selçuk University, Konya, Turkey \\ ${ }^{3}$ Department of Restorative Dentistry, Faculty of Dentistry, Kırıkkale University, Kırıkkale, Turkey \\ ${ }^{4}$ Research Center, Faculty of Dentistry, Selçuk University, Konya, Turkey \\ ${ }^{5}$ Department of Periodontology, Faculty of Dentistry, Selçuk University, Konya, Turkey \\ Corresponding author, Meral ARSLAN MALKOÇ; E-mail: mrlmalkoc@hotmail.com
}

To evaluate the cytotoxicity of resin cements on dental pulp-derived cells (bDPCs), Bifix QM (BQM), Choice 2(C2), RelyX U200(RU200), Maxcem Elite(ME), and Multilink Automix(MA) were tested. The materials were incubated in DMEM for $72 \mathrm{~h}$. A real-time cell analyzer was used to evaluate cell survival. The statistical analyses used were one-way ANOVA and Tukey-Kramer tests. BQM, RU200, and ME demonstrated a significant decrease in the bDPCs' index at 24 and $72 \mathrm{~h}(p \leq 0.001)$. These materials were found to be the most toxic resin cements, as compared to the control and other tested materials (C2 and MA). However, C2 and MA showed a better survival rate, compared to BQM, RU200, and ME, and had lower cell index than the control group. The cytotoxic effects of resin cements on pulpa should be evaluated during the selection of proper cements.

Keywords: Cytotoxicity, Resin cements, Real-time cell analysis, Dental pulp-derived cells

\section{INTRODUCTION}

Dental resin cements are used for the luting of conventional and full ceramic crowns, inlay, onlay, and laminate veneers during clinical practice. Resin cements demonstrated superior features, such as high bond strength, lower oral solubility, and higher micromechanical-chemical bonding to tooth structures and restoration ${ }^{1)}$. This connection decreases microleakage, postoperative sensitivity, marginal staining, and recurrent caries, and it provides reinforcement between restoration and tooth ${ }^{2)}$.

Because the resin materials are located close to the pulpal tissue and have prolonged contact with the freshly cut dentin-pulpal complex, their impact on pulpal cells is of great interest, especially when the dentin is thin or pulp exposure is noted during tooth preparation ${ }^{3,4)}$. Toxic elements released from these cements may result in a reaction in the adjacent tissues, such as the pulp, gingiva, alveolar bone, or mucosa. The cytotoxicity of resin-based restorative materials has been extensively studied, but only a few studies on the cytotoxicity of resin luting cements have been presented. The toxicities of the resin luting cements have been evaluated, and different test methods and cells, including the murine fibroblast cell line L9295), primary cultures of human lymphocytes ${ }^{6)}$, human gingival fibroblasts ${ }^{7}$, and human dental pulp cell cultures $^{3)}$ have been utilized. In previous experiments, several methods were used to evaluate the cytotoxicity of resin materials: lactate dehydrogenase (LDH) assay ${ }^{8}$, benzol-disulfonate (WST-1) assay ${ }^{9}$, benzene sulfonic

Color figures can be viewed in the online issue, which is available at J-STAGE.

Received Jun 11, 2014: Accepted Sep 26, 2014

doi:10.4012/dmj.2014-167 JOI JST.JSTAGE/dmj/2014-167 acid hydrate assay, tetrazolium bromide (MTT) assay ${ }^{10)}$, bromodeoxiuridine (BrdU) assay ${ }^{8}$, and fluorescence microscopy ${ }^{11,12)}$. The main limitation of these methods is that single-value endpoint qualitative measures of cell fitness were used. The established assays are labor-intensive, and they are comprised of a number of manipulation steps that can potentially lead to variation of the endpoints. Real-time cell analysis demonstrated the physiological state of the cells ${ }^{12)}$. In the $\mathrm{xCELLigence}$ system, the kinetic control of the cellular status during experimental runs reveals continuous information about cell growth, morphological changes, and cell death ${ }^{12)}$.

Although the important developments and improvements of resin cements are satisfying, their biocompatibility is an important question to determine for applicability in dentistry. In our present study, we directed experiments to investigate the cytotoxicity of dental resin cements on dental pulp-derived cells (bDPCs) through real-time and continuous monitoring of cell vitality.

\section{MATERIALS AND METHODS}

\section{Test materials}

Five different dental luting resin cements were tested in this experiment: Bifix QM (Voco, Cuxhaven, Germany), Choice 2 (Bisco, Schaumburg, IL, USA), Rely XU 200 (3M ESPE, St. Paul, MN, USA), Maxcem Elite (Kerr Italia, Scafati, Italy), and Multilink Automix (Ivoclar Vivadent, Schaan, Liechtenstein). Material details and ingredients are provided in Table 1. Test specimens were prepared according to the manufacturers' recommendations using standard Teflon disk $5 \mathrm{~mm}$ 
Table 1 Resin cements used in this study

\begin{tabular}{|c|c|c|}
\hline Materials & Manufacturers & Ingredients $\Upsilon$ \\
\hline Bifix QM & Voco, Cuxhaven, Germany & HEDMA, Bis-GMA, Catalist \\
\hline Choice 2 & $\begin{array}{l}\text { Bisco - Schaumburg, } \\
\text { Illinois, USA }\end{array}$ & $\begin{array}{c}\text { Strontium Glass, amorphous Silica, } \\
\text { Bis-GMA }\end{array}$ \\
\hline Rely X U200 & $\begin{array}{l}\text { 3M ESPE, St. Paul, } \\
\text { Minnesota, USA }\end{array}$ & $\begin{array}{l}\text { Silane treated glass powder, substituted dimethacrylate, } \\
\text { 1-benzyl-5-phenyl-barbic-acid, calcium salt, 1,12-dodecane } \\
\text { dimethycrylate, sodium p-toluene sulfinate, silane treated silica, } \\
\text { calcium hydroxide, methacrylated aliphatic amine, titanium dioxide }\end{array}$ \\
\hline Maxcem Elite & $\begin{array}{l}\text { Kerr Italia, } \\
\text { Scafati, Italy }\end{array}$ & $\begin{array}{l}\text { methacrylate ester monomers, } \\
\text { inert mineral fillers, Ytterbium Fluoride, activators, } \\
\text { stabilizers and colorants }\end{array}$ \\
\hline Multilink Automix & $\begin{array}{l}\text { IvoclarVivadent, } \\
\text { Schaan, Liechtenstein }\end{array}$ & $\begin{array}{c}\text { Bis-GMA, HEMA, } \\
\text { 2-dimethylaminoethyl methacrylate }\end{array}$ \\
\hline
\end{tabular}

HEDMA: hexamethylenedimethacrylate, Bis-GMA: bisphenyl-A-glycidyl methacrylate,

HEMA: 2-hydroxyethyl methacrylate

in width and $2 \mathrm{~mm}$ in depth. All test specimens were set and manipulated under disinfected conditions. Specimens that required light curing were polymerized by a standard light-emitting diode curing unit (Elipar Free Light 2, 3M ESPE Dental Products, St Paul, MN, USA). Ten specimens were used in each testing group.

\section{Cell culture}

The bDPCs (cells were named "SVNeo3 cells" by the group) were kindly provided by Professor G. Schmalz (Regensburg University) ${ }^{2}$, and were cultured in $\alpha-\mathrm{MEM}$ supplemented with $20 \% \mathrm{FBS}$, penicillin (150 IU/mL), geneticin $(0.1 \mathrm{mg} / \mathrm{mL})$, and streptomycin $(150 \mu \mathrm{g} / \mathrm{mL})$ at $37^{\circ} \mathrm{C}$ and $5 \% \mathrm{CO}_{2}$. Cells within passages 19 to 23 were used.

\section{Cytotoxicity testing}

The specimens were immersed in $7 \mathrm{~mL}$ of culture medium for $24 \mathrm{~h}$ at $37^{\circ} \mathrm{C}$ to extract residual monomer or cytotoxic substances. The culture medium containing the material extracts was sterile and filtered for use on the cell cultures. The test procedures for this investigation were regulated by ISO standard 10993- $5^{13)}$.

The xCELLigence system (Roche Applied Science, Mannheim, Germany, and ACEA Biosciences, San Diego, CA, USA) consists of four main modules: the impedance-based real-time cell analyzer (RTCA), the RTCA single plate, the RTCA computer, and E-plate 96. The RTCA single plate was placed in a tissue-culture incubator. The electronic impedance of the sensor electrodes was measured to allow for the monitoring and detection of physiological changes in the cells. The voltage applied to the electrodes during the RTCA measurement was $20 \mathrm{mV}$. The impedance measured between the electrodes in each well depended upon electrode geometry, ion concentration in the well, and whether the cells were attached to the electrodes. In the absence of cells, electrode impedance was mainly determined by the ion environment, both at the electrode-solution interface and in the bulk solution. In the presence of cells, the cells attached to the electrode sensor surfaces acted as insulators, thereby altering the local ion environment at the electrode-solution interface and leading to increased impedance ${ }^{12,14)}$.

The tested material samples $(5 \times 2-\mathrm{mm}$ disks of each material) were incubated in a DMEM culture medium for $72 \mathrm{~h}$ according to ISO 10993-5 standards (surface area-to-volume ratio of the specimen to cell-culture medium: $3 \mathrm{~cm}^{2} / \mathrm{mL}$ ). bDPCs were maintained in DMEM containing $10 \%$ fetal bovine serum. The xCELLigence system was used to assess cell survival. After seeding $200 \mathrm{~mL}$ of the cell suspensions into the wells $(7,500$ cells/well) of the E-plate 96, bDPCs were treated with bioactive components released by the testing of the luting cement materials, and were monitored every 15 $\min$ for $72 \mathrm{~h}$.

\section{Cell morphology evaluation}

The morphologic alteration of bDPCs was observed directly using an inverted microscope (TS100 Nikon Eclipse, Tokyo, Japan) (10×) and photographed with a camera (Nikon Eclipse, Tokyo, Japan).

\section{Scanning electron microscopic evaluation}

To evaluate the morphology and adhesion of bDPCs (100,000 cells $(25 \mu \mathrm{L}) /$ resin discs), cells were seeded on the luting resin cements, which were placed on the tissue culture inserts. The adhesion of cells was assessed with a scanning electron microscope (SEM). For this evaluation, cells were fixed on resin cements for $15 \mathrm{~min}$ with $2.5 \%$ gluteraldehyde in 0.01-M PBS. After removal from the inserts, the specimens were dried and sputtercoated with gold. The surface of the resin cements and the adhesion profile of the bDPCs were photographed 
with an SEM (Zeiss EVO ${ }^{\circledR}$ LS 10, Brock \& Michelsen, Denmark).

\section{Statistical analysis}

Data are represented as mean (m mol/L) \pm SD. For the proliferation experiments, the one-way analysis of variance (ANOVA) and Tukey-Kramer multiple comparison tests were used. A value of $p<0.05$ was considered to be statistically significant at $\alpha=0.05$.

\section{RESULTS}

All the tested luting resin-based cements were cytotoxic on bDPCs, but the extent of the effects varied between the materials (Fig. 1). Bifix QM, RelyX U200, and Maxcem Elite led to significant decreases in the bDPCs' index at 24 and $72 \mathrm{~h}(p \leq 0.001)$, and these materials were found to be the most toxic resin cements, compared to the control and other tested materials (Choice 2 and Multilink Automix). However, Choice 2 and Multilink Automix showed better survival rates, compared to Bifix
QM, RelyX U200, and Maxcem Elite, and had lower cell index values than the untreated control group (Fig. 1, Table 2).

Under light microscopy, bDPCs were elongated and spindle-shaped in appearance. While Bifix and Choice 2 led to the expansion of the intercellular gap, the cells preserved their spindle shape. Cell density decreased in the tested groups, compared to the control group. Light microscopy images confirmed the RTCA results. As the toxicity increased, cells exhibited a rounded shape, meaning that they were not alive, especially in Bifix QM, Maxcem Elite, and RelyX U200 (Fig. 1).

During SEM examination, cells exhibited an ovoid to rounded morphology, with cytoplasmic extensions adapting to the resin cements. Attached cells produced a better extracellular matrix on Bifix QM, Choice 2, and Multilink Automix than RelyX U200 and Maxcem Elite. Viable cells attached to Choice 2 and Multilink Automix were more numerous than in other groups (Fig. 3).

\section{Cell index at 72 hours}

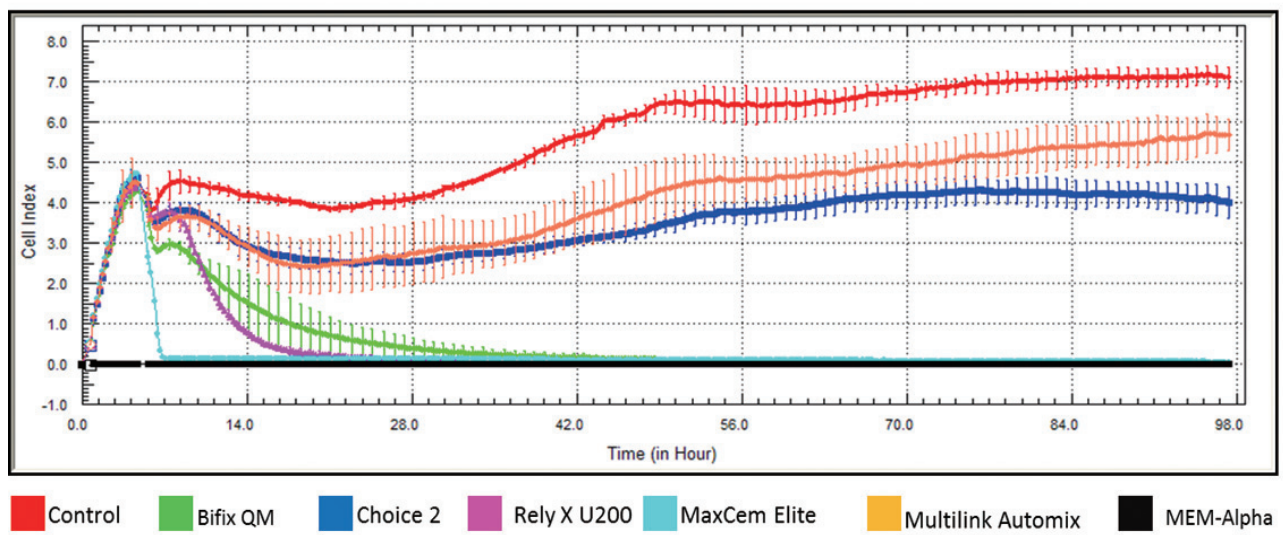

Fig. 1 Dynamic monitoring of the adhesion and proliferation of bDPCs.

Table 2 Cell index by real time cell analysis and comparison of 24 and $72 \mathrm{~h}$ with ANOVA and Tukey Krammer multiple comparison tests

\begin{tabular}{lcc}
\hline Groups $(n=10)$ & $\begin{array}{c}24 \mathrm{~h} \\
\text { Mean } \pm \mathrm{SD}\end{array}$ & $\begin{array}{c}72 \mathrm{~h} \\
\text { Mean } \pm \mathrm{SD}\end{array}$ \\
\hline Control & $3.966 \pm 0.099$ & $6.850 \pm 0.191$ \\
Bifix QM & $0.552 \pm 0.380 * * *$ & $0.059 \pm 0.039 * * *$ \\
Choice 2 & $2.542 \pm 0.258 * *$ & $4.234 \pm 0.354 * *$ \\
Rely X U200 & $0.169 \pm 0.073 * * *$ & $0.031 \pm 0.005 * * *$ \\
Maxcem Elite & $0.147 \pm 0.007 * * *$ & $0.089 \pm 0.019 * * *$ \\
Multilink Automix & $2.350 \pm 0.702 * *$ & $4.909 \pm 0.376 * *$ \\
\hline
\end{tabular}

h: hours, SD : standard deviation, ${ }^{*}: p<0.05,{ }^{* *}: p<0.01,{ }^{* * *}: p<0.001$, 


\section{day 1}
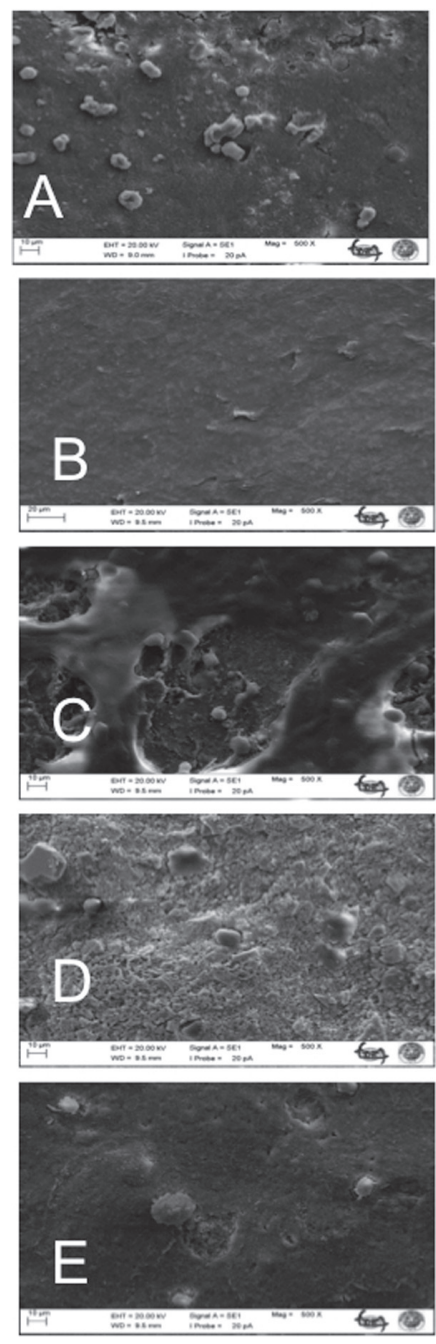

day3
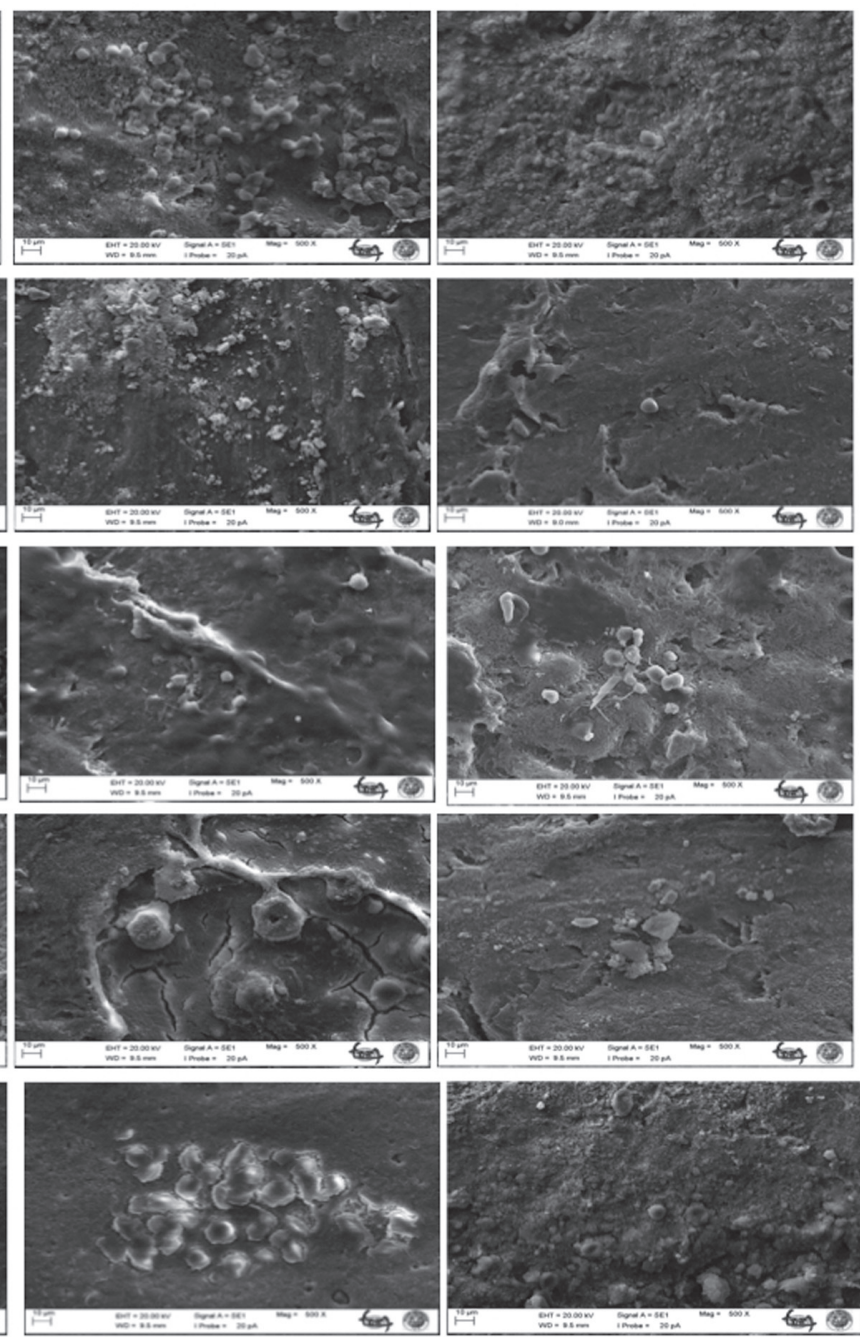

day 7

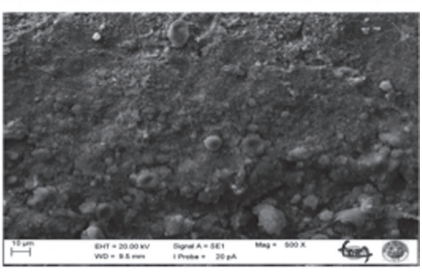

Fig. 2 SEM images of cultured bDPCs.

A) Bifix QM; B) Choice 2; C) RelyX U200; D) Maxcem Elite; and E) Multilink Automix.

\section{DISCUSSION}

The current study demonstrated that many resinbased dental cement materials create toxic reactions in different cell cultures ${ }^{1-3,7,16)}$. The effects of five different luting resin cements on bDPCs were investigated, using the same standardized real-time xCELLigence test system for each. The research clearly showed that Bifix QM, RelyX U200, and Maxcem Elite were more toxic than other tested materials. Choice 2 and Multilink Automix were also cytotoxic materials, compared to the control.

Up until now, the reaction of cultured pulp cells to resin-based luting cements has not been adequately studied. It is critical to determine the effects of resinbased cements on cells derived from oral tissues, such as pulp cells, because luting cement materials are located close to pulp tissues. Especially, freshly cut dentin surfaces and opened dentinal tubules are exposed after the enamel layer has been removed during preparation for crowns. The main purpose of luting cements is to cement a fixed restoration to a prepared tooth surface. Additionally, these materials must contribute to protecting the exposed enamel, dentin, and pulpal tissues from thermal, mechanical, and microbial effects, as well as maintain phonetics, aesthetics, and masticatory function ${ }^{16,17)}$.

Several in vitro cytotoxicity study models, such as inhibition of cell growth, effects of membrane or cytoplasmic marker cytolysis, mitochondrial dehydrogenase of active cells, and changes in metabolic activity, have been designed in the past 30 years to overcome the disadvantages of in vivo study designs, which evaluate biological response to different dental 


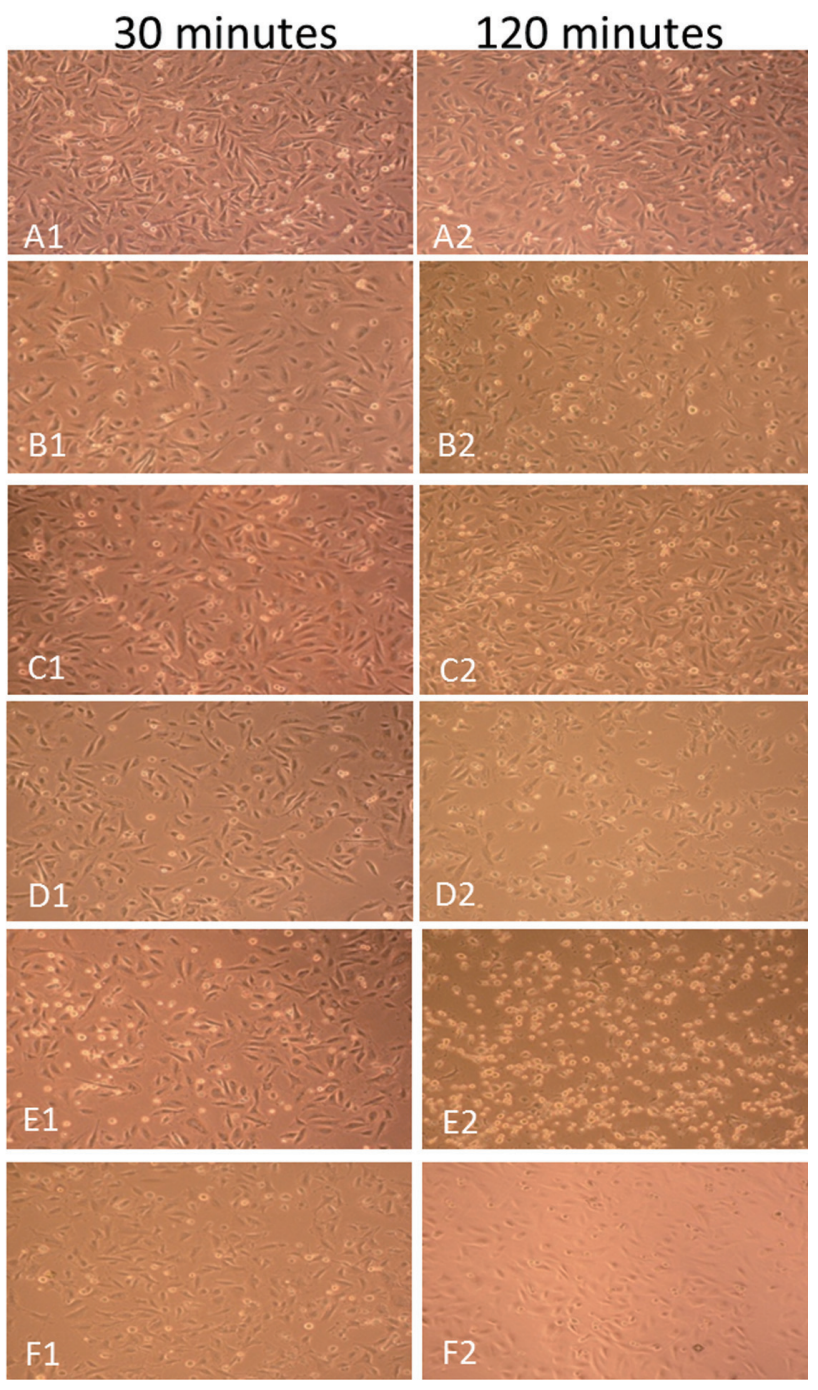

Fig. 3 Light microscope images of cultured bDPCs.

1) $30 \mathrm{~min}$; 2) $120 \mathrm{~min}$; A) Control; B) Bifix QM;

C) Choice 2; D) RelyX U200; E) Maxcem Elite; and

F) Multilink Automix.

materials ${ }^{14,18)}$. The main advantages of cell culture tests are standardization, high reproducibility, adequate sample sizes, and the absence of ethical considerations ${ }^{7,14,19)}$. Only one test design is appropriate for examining one type of unwanted effect on a variety of possible reactions. Additionally, specific test methods are usually acceptable only for defining a single aspect of a certain type of unwanted reaction ${ }^{19)}$. We designed experiments using a new real-time system that studied the cytotoxicity of 2 -hydroxyethyl methacrylate (HEMA) and other toxic ingredients on bDPC pulp cells through real-time, uninterrupted observations of cell growth, proliferation, and vitality.

Real-time and uninterrupted observation allows for the free evaluation of cell proliferation, vitality, toxicity, the demonstration of the physiological situation of the cells, and the avoidance of expensive reagents used in traditional cell analyses. In this test design, the observer has dynamic control of the cellular condition, and nonstop data regarding cell growth, development, morphologic alterations, and cell death is provided. In addition, RTCA allows for the calculation of time-related physiological values, which can provide more knowledge than the single-value endpoints of current toxicity testing ${ }^{12,14)}$. In comparison to traditional endpoint cellbased assays, dynamic monitoring of cell reactions, such as cell adhesion, increasing, proliferation, growth, and apoptosis, is an advantage of the real-time design that allows for the optimization of cell concentration and conditions for in vitro assays before and during the experiment. Furthermore, the reaction of live cells to chemical exposure can be observed in real-time, which is not possible with current endpoint assays, such as LDH, MTT, XTT, WST-1, or BrdU viability assays. The real-time test method proved to be useful for estimating cell densities in small culture volumes. Cultivation in small culture volumes and sensitive evaluation using a real-time test allow for the screening and testing of many different substances and fractions, to determine cytotoxicity $^{12,14)}$. For these reasons, we preferred a realtime $\mathrm{xCELLigence} \mathrm{test.}$

Primary pulp cells are very similar to the original tissue, and they have unchanged metabolic conditions. Therefore, an in vivo condition may be better mimicked by primary pulp cells. However, the isolation of primary cells from pulpal tissue is labor-intensive, timeconsuming, and the resulting cell amounts are often low in comparison with those achieved from cell lines. Moreover, primary pulp cells do not have the potential to divide and reach anon-proliferative status. Recently, to solve this problem, an immortalized bovine dental papilla-derived cell line was developed by transfection with the coding sequences of a Simian Virus 40 (SV40) large T-antigen ${ }^{15,20)}$. A major problem with this method is that the developed cell line may be not the same as the original tissue. However, this cell line was demonstrated to have the same biological features as primary dental pulp cells. Consequently, this cell line could be a viable choice for biocompatibility studies of dental materials ${ }^{21)}$.

In the present study, the cytotoxicity of elutes of five different resin-based luting cements to pulp cells was evaluated using the real-time xCELLigence system. It was found that all the tested resin cements were cytotoxic to pulp cells. Although the test design and investigation conditions of the present study were different from those of other studies, the results are in accordance with previous studies ${ }^{1-3,7,15)}$.

The matrix of resin cements contains different monomers, such as bisphenol-A-glycidyl methacrylate (Bis-GMA) and/or 1,6-bis(methacrylyloxy-2ethoxycarbonylamino)-2,4,4-trimethylhexane (UDMA). Other components of the composite matrix are comonomers, including ethyleneglycoldimethacrylate (EGDMA), diethyleneglycoldimethacrylate (DEGDMA), Triethyleneglycol dimethacrylate (TEGDMA), and additional additives such as co-initiators, photo initiators, inhibitors, and color pigments. TEGDMA 
decreases the viscosity of the resin matrix, thus allowing for increased filler content. These ingredients may alter cell metabolism at concentrations well under the toxic threshold, and the observed changes may be assumed to be potential mechanisms for inducing adverse clinical effects $^{22,23)}$.

Resin-based cements were examined using different toxicity tests. It was found that these materials were differently cytotoxic in different cells, such as human gingival fibroblast or pulp cells. Hydrophilic substances, such as HEMA and TEGDMA, were more toxic, since these monomers easily diffuse through dentin ${ }^{23)}$. Adequately effective concentrations in the pulp may cause tissue damage ${ }^{24)}$. Unwanted pulpal reactions may occur when dentin thickness is low and tubules are open after tooth preparation for luting of fixed restorations with resin-based cements ${ }^{24}$. Regarding clinical relevance, low pulp volumes will result in comparably high local concentrations, even if only small amounts of the substances diffuse through the dentin.

Bifix QM contains adhesive monomers, including hexamethylenedimethacrylate (HEDMA) and BisGMA. Extracts of Bifix QM decreased the vitality of bDPCs; thus, this cement was highly toxic among the tested materials. No data could be found regarding the cytotoxicity of HEDMA or Bifix QM. Choice 2 was also cytotoxic after exposure to cultured bDPCs. Choice 2 is a dual-cure resin cement based on Bis-GMA. It has been reported that Bis-GMA is cytotoxic to fibroblasts when dissolved in inorganic solvents ${ }^{2,7)}$. Also, BisGMA precursors that exhibited cytotoxic effects led to potentially adverse biological reactions. Furthermore, various ions are leached out at different times and in different conditions.

In the current study, we found that the dual-cure resin luting cement RelyX U200 was also cytotoxic to bDPCs. In accordance with our results, previous studies $^{2,5,25)}$ reported that RelyX U200 presented cytotoxic effects in different cell lines, such as odontoblast, fibroblast, and pulp cells. RelyX U200 contains a multifunctional phosphoric-acid-modified methacrylate. In agreement with our investigation, Bakopoulou et $a l .{ }^{26)}$ demonstrated that eluates of RelyX U200 were severely cytotoxic, as the first serial dilution of RelyX U200 caused complete mitotic arrest in lymphocyte cultures. Cementation of inlays using RelyX U200 caused mild inflammatory pulp response in an in vivo study ${ }^{25)}$.

Maxcem Elite contains methacrylate ester adhesive monomers. Extracts of Maxcem Elite highly decreased the vitality of bDPCs, thus presenting as the material with the highest cytotoxicity within the tested series. This agrees with the conclusions of Schmid-Schwap et $a l .{ }^{5)}$ and Ülker et $a l .{ }^{2)}$, which showed that Maxcem Elite demonstrated high toxicity. However, in contrast to these results, Ülker and Sengun ${ }^{16)}$ assessed the toxicity of Maxcem Elite through a dentin barrier test, concluding that Maxcem Elite was not cytotoxic to a 3D pulp cell culture. Ülker and Sengun ${ }^{16)}$ placed a $500-\mu \mathrm{m}$ dentin barrier between the test material and the target cells.

Finally, Multilink Automix, which contains dimethacrylates and HEMA, was also cytotoxic. Some studies concerning the biodegradation of HEMA have been conducted ${ }^{7)}$. Water-soluble extracts are used in different resin-based adhesives, such as HEMA, and they are released from the materials. Swallowed HEMA was nearly totally absorbed by the organism, and it was determined to be cytotoxic due to its diffusion through oral tissues ${ }^{7}$.

The test design of this investigation demonstrated that resin-based luting cements are capable of eliciting biological responses. bDPCs could be affected by extracts released by cements. The main targets of this experiment were to evaluate the cytotoxicity of resinbased dental cements using a standardized test method, and to recognize and compare their toxic potentials. Currently, there is no data regarding the correlation between the clinical effects and cytotoxicity of resin cements in pulpal, dentin, and gingival tissue. Thus, toxic destruction occurring in clinical situations relies upon the amount of cement located near oral tissues, and upon the amount of toxic extracts. In addition, the individual sensitivities or tolerances of patients might affect the results.

\section{CONCLUSION}

The results presented in this study indicate that, depending upon the remaining dentin thickness after tooth preparations in clinical situations, biologically active resin monomers or extractions released from resin luting cements may influence pulpal tissue, especially regarding its regenerative and reparative capacities. However, various cytotoxic effects of resin luting cements on the pulpal tissue should be evaluated during the selection of resin cements for luting fixed restoration.

\section{REFERENCES}

1) Anchieta RB, Rocha EP, de Almeida EO, Junior AC, Martini AP. Bonding all-ceramic restorations with two resins cement techniques: a clinical report of three-year follow-up. Eur $\mathrm{J}$ Dent 2011; 5: 478-485.

2) Ülker HE, Hiller KA, Schweikl H, Seidenader C, Sengun A, Schmalz G. Human and bovine pulp-derived cell reactions to dental resin cements. Clin Oral Investig 2012; 16: 15711578.

3) Kong N, Jiang T, Zhou Z, Fu J. Cytotoxicity of polymerized resin cements on human dental pulp cells in vitro. Dent Mater 2009; 25: 1371-1375.

4) Malkoc M, Keles A, Karagoz S, Polat N. An examination of the heat-conductive properties of temporary luting cements. SÜ Dișhek Fak Derg 2013; 22: 27-33.

5) Schmid-Schwap M, Franz A, König F, Bristela M, Lucas T, Piehslinger E. Cytotoxicity of four categories of dental cements. Dent Mater 2009; 25: 360-368.

6) Bakopoulou A, Mourelatos D, Tsiftsoglou AS, Giassin NP, Mioglou E, Garefis P. Genotoxic and cytotoxic effects of different types of dental cement on normal cultured human lymphocytes. Mutat Res 2009; 672: 103-112.

7) Malkoc S, Corekci B, Botsali HE, Yalcin M, Sengun A. Cytotoxic effects of resin-modified orthodontic band adhesives. 
Are they safe? Angle Orthod 2009; 80: 890-895.

8) Reichl FX, Simon S, Esters M, Seiss M, Kehe K, Kleinsasser $\mathrm{N}$. Cytotoxicity of dental composite (co)monomers and the amalgam component $\mathrm{Hg} 2+$ in human gingival fibroblasts. Arch Toxicol 2006; 80: 465-472.

9) Boland EJ, MacDougall M, Carnes DL, Dickens SH. In vitro cytotoxicity of a remineralizing resin-based calcium phosphate cement. Dent Mater 2006; 22: 338-345.

10) Schwengberg S, Bohlen H, Kleinsasser N, Kehe K, Seiss M, Walther UI. In vitro embryotoxicity assessment with dental restorative materials. J Dent 2005; 33: 49-55.

11) Reichl FX, Esters M, Simon S, Seiss M, Kehe K, Kleinsasser N. Cell death effects of resin-based dental material compounds and mercurials in human gingival fibroblasts. Arch Toxicol 2006; 80: 370-377.

12) Urcan E, Haertel U, Styllou M, Hickel R, Scherthan H, Reichl FX. Real-time xCELLigence impedance analysis of the cytotoxicity of dental composite components on human gingival fibroblasts. Dent Mater 2010; 26: 51-58.

13) ISO 10993-5: 2009.

14) Malkoç S, Öztürk F, Çörekçi B, Bozkurt BS, Hakki SS. Real-time cell analysis of the cytotoxicity of orthodontic mini-implants on human gingival fibroblasts and mouse osteoblasts. Am J Orthod Dentofacial Orthop 2012; 141: 419426.

15) Sengün A, Yalçın M, Ülker HE, Öztürk B, Hakkı SS. Cytotoxicity evaluation of dentin bonding agents by dentin barrier test on 3-dimensional pulp cells. Oral Surg Oral Med Oral Pathol Oral Radiol Endod 2011; 112: 83-88.

16) Ulker HE, Sengun A. Cytotoxicity evaluation of self adhesive composite resin cements by dentin barrier test on $3 \mathrm{D}$ pulp cells. Eur J Dent 2009; 3: 120-126.

17) Seelbach P, Finger WJ, Ferger P, Balkenhol M. Temperature rise on dentin caused by temporary crown and fixed partial denture materials: influencing factors. J Dent 2010; 38: 964973.

18) Hensten-Pettersen A. Comparison of the methods available for assessing cytotoxicity. Int Endod J 1988; 21: 89-99.

19) Jonke E, Franz A, Freudenthaler J, Konig F, Bantleon HP, Schedle A. Cytotoxicity and shear bond strength of four orthodontic adhesive systems. Eur J Orthod 2008; 30: 495502.

20) Galler KM, Schweikl H, Thonemann B, D’Souza RN, Schmalz G. Human pulp-derived cells immortalized with Simian Virus 40 T-antigen. Eur J Oral Sci 2006; 114: 138-146.

21) Thonemann B, Schmalz G. Immortalization of bovine dental papilla cells with simian virus 40 large T antigen. Arch Oral Biol 2000; 45: 857-869.

22) Porto ICCM, Oliveira DC, Raele RA, Ribas KHS, Montes MAJR, De Castro CMMB. Cytotoxicity of current adhesive systems: In vitro testing on cell cultures of primary murine macrophages. Dent Mater 2011; 27: 221-228.

23) Schmalz G. Cements and ceramics. In: Schmalz G, ArenholtBindlev D, eds. Biocompatibility of Dental Materials. Berlin, Germany: Springer; 2009: 139-187.

24) Al-Fawaz, A, Gerzina TM, Hume WR. Movement of resin cement components through acid-treated dentin during crown cementation in vitro. J Endod 1993; 19: 219-223.

25) De Mendonça AA, Souza PP, Costa CA. Cytotoxic effects of hard-setting cements applied on the odontoblast cell line MDPC-23. Oral Surg Oral Med Oral Pathol Oral Radiol Endod 2007; 104: 102-108.

26) De Souza Costa CA, Hebling J, Randall RC.Human pulp response to resin cements used to bond inlay restorations. Dent Mater 2006; 22: 954-962. 